\title{
MEMBRANE BLEBBING IN CANCER CELLS TREATED WITH VARIOUS APOPTOTIC INDUCERS
}

\author{
Emil Rudolf, Miroslav Červinka \\ Charles University in Prague, Faculty of Medicine in Hradec Králové, Czech Republic: Department of Medical Biology \\ and Genetics \\ Summary: The dynamics of cell morphology, in particular membrane blebbing, was studied after induction of apoptosis \\ by etoposide or camptothecin in four human stabilized cell lines (Hep2, Bowes, HT-29 and HL-60). Time lapse videomicro- \\ scopy and F-actin staining revealed various dynamic parameters of this process including its duration, maximal extent, \\ stages and final endpoints in individual cells. Although generally occurring in predictable patterns, our results indicate \\ a relatively significant variability both in appearance and temporal organization of blebbing not only between different cell \\ lines but also within them.
}

Key words: Apoptosis; Membrane blebbing; Cytoskeleton; F-actin; In vitro

\section{Introduction}

Many cytostatic drugs have been reported to induce apoptosis in tumor cells both in vitro and in vivo $(1,7,14)$. This process is characterized by several molecular and biochemical features such as up-regulation of pro-apoptotic genes, activation of specific enzymes, degradation of subcellular organelles and DNA fragmentation (4). Furthermore, dramatic changes in appearance of dying cells include cell contraction and rounding, formation of spikes and blebs and final cell fragmentation into apoptotic bodies (3).

Plasma membrane blebbing is, perhaps, the most characteristic feature of apoptotic cells. However, its dynamics as well as occurrence in different cells is not entirely explored. Here we present pilot results of a detailed, morphological analysis of apoptotic blebbing in several tumor cell lines (Hep-2, Bowes, HT-29 and HL-60) treated with cytostatic drugs etoposide or camptothecin. Time-lapse recordings and immunofluorescent staining of actin fibers show that the timing and course of cytoskeletal changes and resulting apoptotic blebbing differ not only in various cell lines but also within them, with individual blebbing figures being dependent on many factors.

\section{Materials and methods}

\section{Cell lines and treatment with cytostatics}

Human epitheloid cell line Hep2 (ECACC, No. 86030501, Porton Down, England) was cultivated as stationary monolayer in plastic tissue-culture dishes (Nunclon,
Danemark). Cells were grown in Dulbecco's modified Eagle's medium (Gibco, Germany) supplemented with 10\% fetal serum (Gibco, Germany), $100 \mathrm{U} / \mathrm{ml}$ penicillin, and $100 \mu \mathrm{g} / \mathrm{ml}$ streptomycin.

Bowes human melanoma cell line (ATCC, No. CRL 9607, Manassas, United States) was grown as adherent cell culture in DMEM PAN (Gibco, Germany) supplemented with $10 \%$ fetal bovine serum (Gibco, Germany), $100 \mathrm{U} / \mathrm{ml}$ penicillin, and $100 \mu \mathrm{g} / \mathrm{ml}$ streptomycin.

Human colon adenocarcinoma HT-29 cells (ATCC, No. HTB - 38 Manassas, United States) were maintained in monolayer in Dulbecco's modified Eagle's medium (Gibco, Germany) supplemented with $10 \%$ fetal serum (Gibco, Germany), $100 \mathrm{U} / \mathrm{ml}$ penicillin, and $100 \mu \mathrm{g} / \mathrm{ml}$ streptomycin.

Human promyelocytic leukemia HL-60 cells (ECACC, No. - 85011431, Porton Down, England) were grown in RPMI 1640 medium (Gibco, Germany) supplemented with $10 \%$ fetal calf serum (Gibco, Germany), $100 \mathrm{U} / \mathrm{ml}$ penicillin, and $100 \mu \mathrm{g} / \mathrm{ml}$ streptomycin.

Etoposide (Vepesid inj., Bristol-Myers Squibb, U.S.A.) was diluted from the original ampoules supplied by manufacturer in a serum-free DMEM to the tested concentration of $10 \mu \mathrm{g} / \mathrm{ml}$.

Camptothecin (Sigma-Aldrich, Czech Republic) was dissolved to the stock concentration of $10 \mathrm{mg} / \mathrm{ml}$ in dimethylsulfoxide (DMSO) (Sigma-Aldrich, Czech Republic) and stored in a dark place at room temperature. The final tested concentration of $10 \mu \mathrm{g} / \mathrm{ml}$ was obtained by diluting the stock concentration in a serum-free DMEM.

Only mycoplasma-free cells were used for experiments. 


\section{Time-lapse videomicroscopy}

Cells were seeded into a $25 \mathrm{ml}$ plastic tissue-culture flask (Nunclon, Roskilde). After a 24h-cultivation period, the cultivation medium was replaced with a medium containing tested chemical (etoposide or camptothecin). The culture flask was subsequently transferred to a $37{ }^{\circ} \mathrm{C}$-heated chamber and cells were examined continuously over the 24h period, using an inverted microscope Olympus IX-70 (Olympus Optical CO, Ltd., Tokyo) equipped with a longworking-distance condenser, and a $20 \mathrm{X}$ phase contrast lens. For time-lapse recording, the microscope was equipped with a Mitsubishi CCD-100E camera (Mitsubishi Corporation, Tokyo) and connected to a Mitsubishi video recorder HS-S5600 (Mitsubishi Corporation, Tokyo). The recording was performed in various modes under different magnifications to allow general as well as detail-focused analysis. The recorded sequences were converted to digitized form by the software Adobe Premiere 6.0 (Adobe Systems Incorporated, San Jose) and analyzed frame by frame.

\section{Visualization of F-actin and cell nucleus}

Cells were seeded into modified cytospin chambers (Hettich, Germany) and allowed to grow overnight at $37^{\circ} \mathrm{C}$ and $5 \% \mathrm{CO}_{2}$ in an incubator. Next, they were treated with cytostatics and at different time intervals analyzed. Briefly, after fixation with $4 \%$ formaldehyde (SigmaAldrich, Prague) solution and permeabilization with phosphate saline buffer with Triton X (Sigma-Aldrich, Prague), TRITC-Phalloidin solution (Sigma-Aldrich, Prague) was added and specimens were incubated at room temperature for $30 \mathrm{~min}$. Then the specimens were post-labeled with DAPI, mounted into SlowFade ${ }^{\circledR}$ medium (Molecular Probes, Inc. Eugene, U.S.A.) and examined under a fluorescence microscope Nikon Eclipse E 400 (Nikon Corporation, Kanagawa, Japan) equipped with a digital color matrix camera COOL 1300 (VDS, Vosskühler, Germany). Photographs were taken using the software LUCIA DI
Image Analysis System LIM (Laboratory Imaging Ltd., Prague, Czech Republic) and analyzed. All the experiments were done in triplicate.

\section{Statistics}

All the experiments were repeated at least three times. Statistical analysis was carried out with a statistical program GraphPad Prism (GraphPad Software, Inc. San Diego, U.S.A.). We used one-way Anova test with Dunnett's post test for multiple comparisons. Results were compared with control samples, and means were considered significant if $\mathrm{P}<0.05$.

\section{Results}

Characteristics of membrane blebbing in Hep-2, Bowes, HT-29 and HL-60 cells. Both etoposide and camptothecin in a given concentration $(10 \mu \mathrm{g} / \mathrm{ml})$ induced cell blebbing and subsequent cell death in all treated cell lines. Particular temporal and spatial characteristics of this process are shown in Tab. 1. In all cell lines, individual cells entered into the blebbing stage always asynchronously, and their total blebbing time varied between $0.3-6 \mathrm{~h}$. There were significant differences in the course of blebbing between cell lines but also within them as in some cells a full scale of up to 8 morphologically distinct stages were recognizable whereas others displayed only a limited number of stages. In addition, in Hep- 2 and HL-60 cell lines, the entire cell population behaved similarly whereas in Bowes and HT-29 cells, the course of blebbing depended on the stratification of cultures, i.e. whether cells existed individually or in larger multicellular clusters. Generally, blebbing started with an increased ruffling activity of the cell membrane followed by the formation of small blebs all over the cell surface. At this stage, cells kept their adherence to the inner surface of cultivation flask (with exception of HL-60 cell line). After varying time intervals, cells lost adherence and formed large membrane blebs (Fig. 1A-D). The number and the

Tab. 1: Spatial and temporal characteristics of membrane blebbing in human cell lines after treatment with etoposide (ETO) or camptothecin (CPT).

\begin{tabular}{|l|c|c|c|c|c|c|c|c|c|}
\hline \multirow{2}{*}{ Cell lines } & \multicolumn{2}{|c|}{$\begin{array}{c}\text { Apoptotic inducer } \\
(\mu \mathrm{g} / \mathrm{ml})\end{array}$} & D $(\mathrm{h})$ & PA $(\%)$ & Ti (h) & Tm (h) & BS (n) & BD (\%) & CHR (\%) \\
& ETO 10 & CPT 10 & & & & & & & \\
\hline Hep2 & $\boldsymbol{V}$ & - & 6 & 50 & 4 & 14 & 8 & 30 & 30 \\
\hline Bowes & - & $\boldsymbol{V}$ & $4^{*}$ & 65 & 10 & 16 & 4 & 70 & 40 \\
\hline HT-29 & - & $\boldsymbol{V}$ & $0.3-0.5$ & $40-60$ & 14 & 24 & Up to $4^{*}$ & 10 & 10 \\
\hline HL-60 & $\boldsymbol{V}$ & - & 2 & 65 & 1 & 4 & 4 & 80 & 60 \\
\hline
\end{tabular}

Values presented in this table were determined from frame by frame analysis of time-lapse recordings and from software analysis of fluorescently labeled specimens. The following parameters were scored: D - average duration of blebbing in individual cells, PA - peak blebbing activity in treated cell population, Ti - time of induction of blebbing, Tm - time to maximal blebbing, BS - number of blebbing stages, BD - detachment of blebs and CHR - redistribution of chromatin into shedded blebs

* depends on morphological stratification of treated culture 

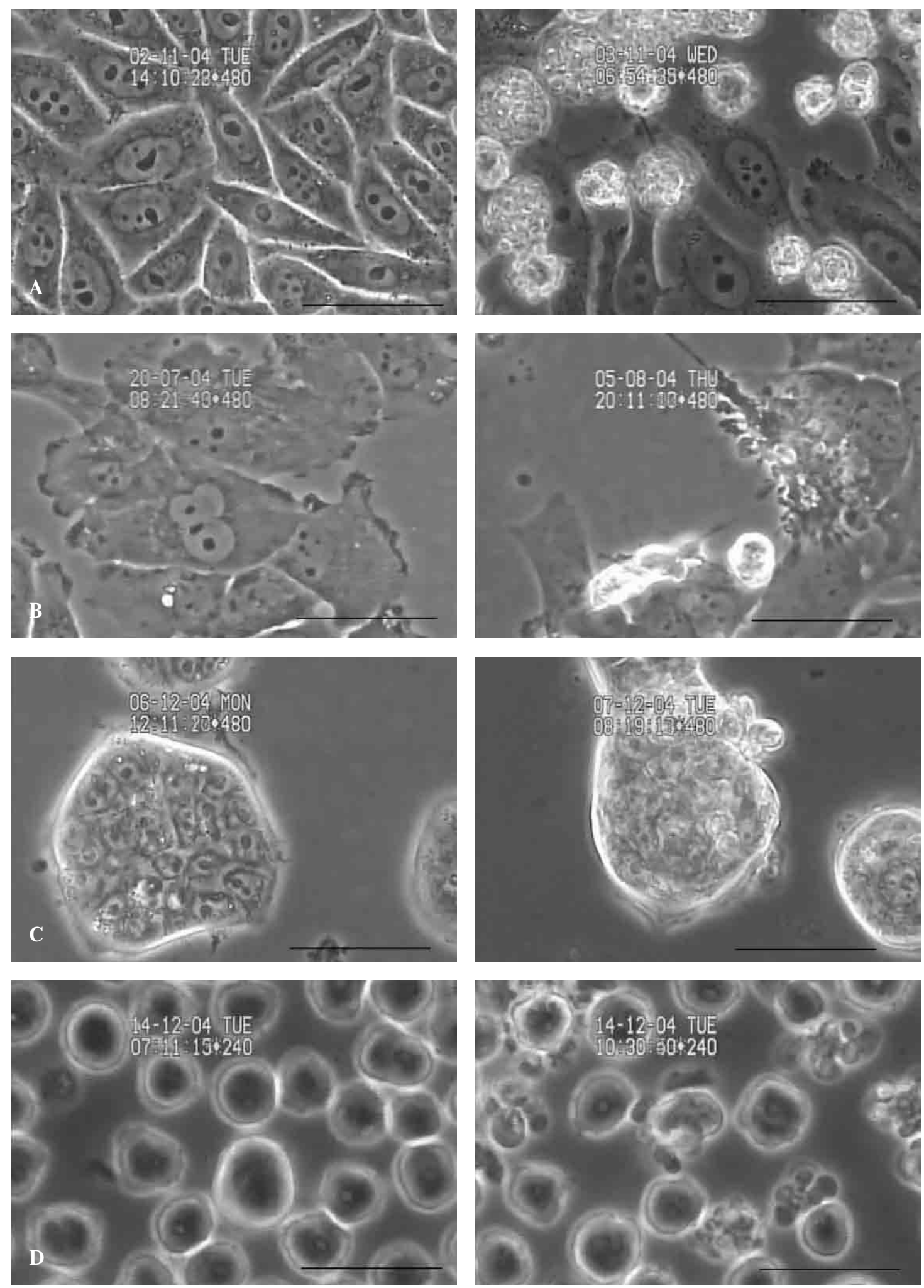

Fig. 1: Apoptotic membrane blebbing in cell lines treated with cytostatics etoposide (ETO) (10 $\mu \mathrm{g} / \mathrm{ml}$ )or camptothecin (CPT) $(10 \mu \mathrm{g} / \mathrm{ml})$. (A) Hep-2 - ETO (B) Bowes - CPT (C) HT-29 - CPT (D) HL-60 - ETO. Left column shows control cells, right column apoptotic blebbing cells. Images represent digitalized printouts of video recordings. Phase contrast, 400x. Bar $50 \mu \mathrm{m}$. 
activity of these blebs showed an extraordinary variability and changed constantly throughout the time. Gradually, cells ceased to produce blebs and remained motionless, in the end undergoing, in some cases, secondary necrosis. Alternatively, blebs became rounded and cells started to shed them, sometimes with enclosed portions of chromatin - so called formation of apoptotic bodies. Of all tested cell lines, HL-60 cell line showed the maximal shedding (80\%) and in approximately $60 \%$ of these shedding cells blebs contained fragmented chromatin. The lowest shedding activity was noted in HT-29 cells (10\%) with roughly equal redistribution of fragmented chromatin. In Bowes cell line, bleb shedding occurred in a relatively large number of cells

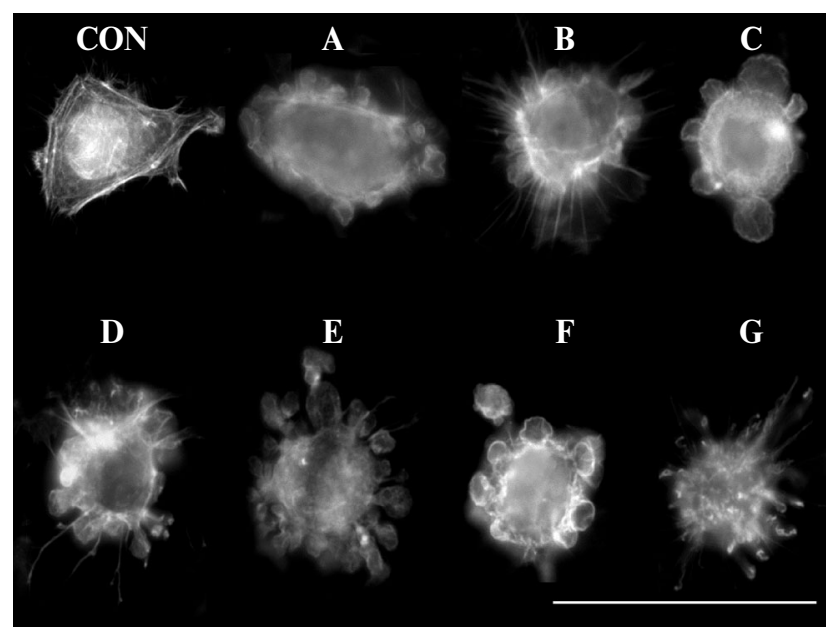

Fig. 2: Types of blebbing figures in Hep-2 cells treated with $10 \mu \mathrm{g} / \mathrm{ml}$ etoposide for $24 \mathrm{~h}$. (CON) Intact cell (A-G) Individual blebbing cells. Immunofluorescent staining of F-actin and nucleus. Fluorescence, 600x. Bar $50 \mu \mathrm{m}$.

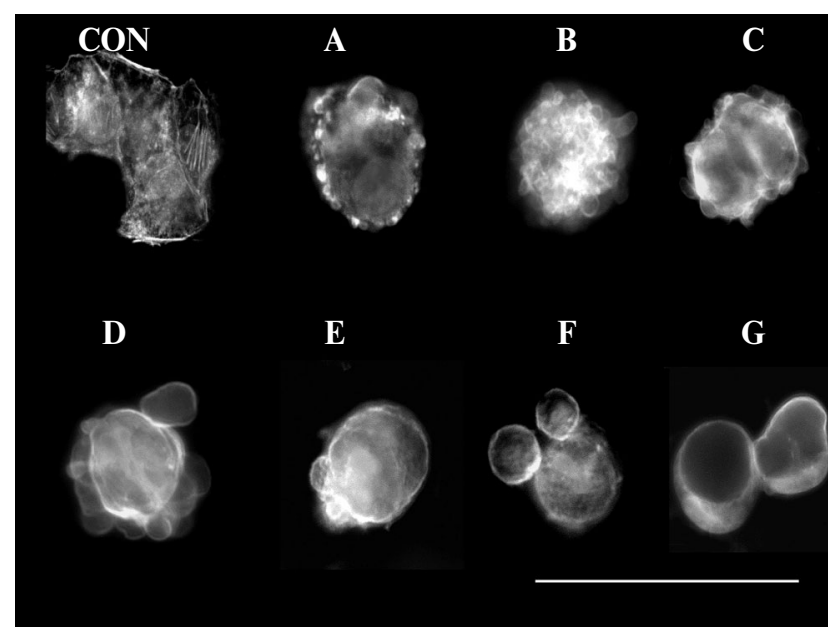

Fig. 4: Types of blebbing figures in HT-29 cells treated with $10 \mu \mathrm{g} / \mathrm{ml}$ camptothecin for $24 \mathrm{~h}$. (CON) Intact cells (A-G) Individual blebbing cells. Immunofluorescent staining of F-actin and nucleus. Fluorescence, 600x. Bar $50 \mu \mathrm{m}$.
(70\%) while only up to $40 \%$ of them contained enclosed chromatin. In Hep-2 cells, the detachment of blebs remained constant $(30 \%)$ as well as chromatin redistribution in them.

Figs. 2,3,4 and 5 depict the most characteristic stages of blebbing in the individual cells of all treated cell lines as they occurred in time.

\section{Discussion}

It is now established that apoptotic membrane blebbing represents one of the most characteristic features of the executory phase of cell death (2,). The presence of membrane blebs has been reported in many experimental systems

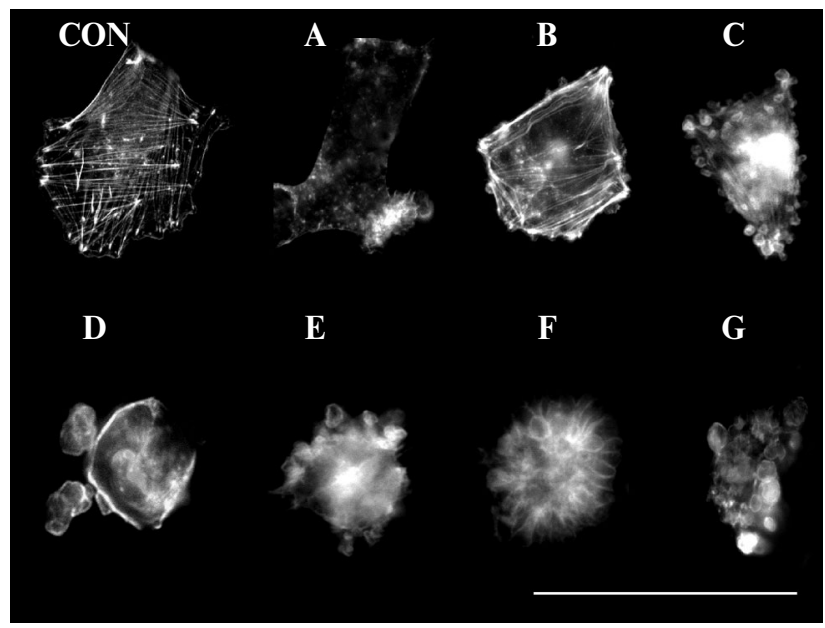

Fig. 3: Types of blebbing figures in Bowes cells treated with $10 \mu \mathrm{g} / \mathrm{ml}$ camptothecin for $24 \mathrm{~h}$. (CON) Intact cell (A-G) Individual blebbing cells. Immunofluorescent staining of F-actin and nucleus. Fluorescence, 600x. Bar $50 \mu \mathrm{m}$.

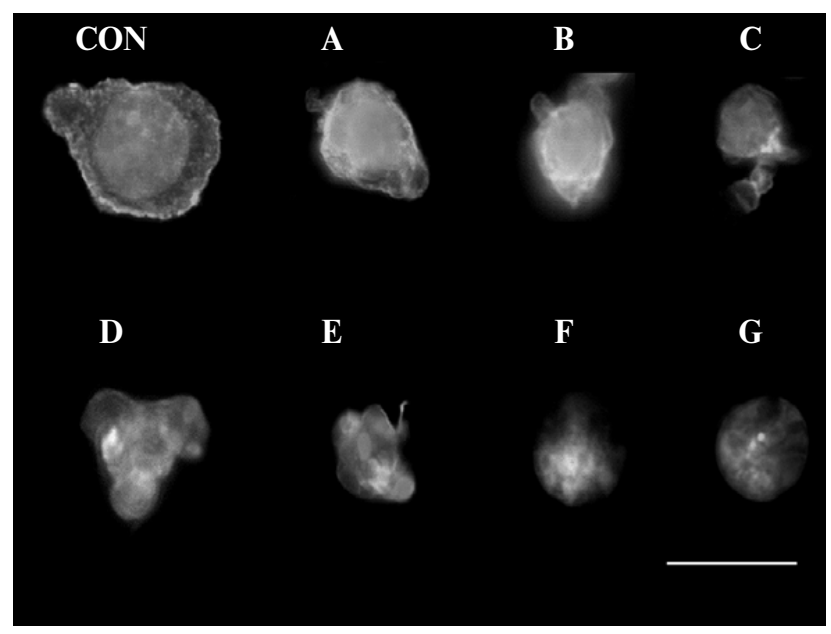

Fig. 5: Types of blebbing figures in HL-60s cells treated with $10 \mu \mathrm{g} / \mathrm{ml}$ etoposide for $24 \mathrm{~h}$. (CON) Intact cell (A-G) Individual blebbing cells. Immunofluorescent staining of F-actin and nucleus. Fluorescence, 600x. Bar $50 \mu \mathrm{m}$. 
upon different treatment conditions $(5,12)$. Still, despite recent progress in our understanding of biochemical and molecular mechanisms underlying morphological changes accompanying cell death, our knowledge of temporal and spatial organization of these changes remains cursory. Furthermore, existing studies are often limited to few model systems and thorough morphological as well as molecular comparisons between different cell types are lacking.

To gain more general and deeper insight into the course of apoptotic blebbing, we carried out a pilot study comprising a series of detailed analyses of blebbing in four different human cell lines - Hep-2, Bowes, HT-29 and HL-60 treated with topoisomerase I (camptothecin) and II (etoposide) inhibitors. The selection of these chemicals and their concentration were based on literature search and our previous experiences with them $(6,13)$.

The course and organization of blebbing were followed using a frame by frame analysis of time-lapse recordings at low (200x) and high (400-600x) magnifications. In addition, immunofluorescent staining of cytoskeleton in treated cells was performed at regular intervals to visualize rearrangement of F-actin, which appears to be a crucial protein involved in formation of membrane blebs. Moreover, the position of chromatin in the cells was visualized to determine whether chromatin is redistributed into apoptotic bodies.

The results of our study show a great variability in the course and appearance of membrane blebbing between employed cell lines (Tab. 1 and Figs. 1,2,3,4 and 5). Furthermore, the similar variability was recorded within each cell line too. The fact that treated cells entered the blebbing stage asynchronously along with our observations that appearance and duration of this phenomenon also vary seems to indicate that several factors are likely to influence it. Among them, the phase of the cell cycle and the particular intracellular signaling profile might be critical. Several authors have shown that membrane blebbing during execution phase of apoptosis is associated with Rho-kinase signaling and depends on the expression of the Rho-associated kinases I (ROCK I) and II (ROCK II) and their cleavage by caspases. These molecules as well as other kinases such as p21-activated protein kinase-2 (PAK2) or LIM-kinases 1 and 2 (LIMK1 and LIMK2) regulate the expression patterns of actin and actin-associated proteins. Changes in these patterns have been reported to underlie actual blebbing process $(8,10,11)$. Since each apoptotic inducer potentially activates selected signaling pathways, it is reasonable to believe that the resulting changes in actin-driven membrane blebbing are bound to vary in different experimental systems upon various treatment conditions. Our results agree with it and this has also been demonstrated in the study where HL-60 cells were treated with two cytostatic drugs operating through distinct mechanisms (3).

In natural environments, cells dying through apoptosis form so called apoptotic bodies which are cleared by macrophages. Apoptotic bodies are defined as small cellular frag- ments with enclosed chromatin (5). Nevertheless, in vitro, apoptotic cells proceed often into secondary necrosis in the absence of apoptotic bodies. In accordance with this scenario, we found that detachment of membrane blebs indicating the formation of apoptotic bodies occurred in $10-80 \%$ of treated cell populations. These detached blebs were found to be chromatin positive from 10 to $60 \%$. Thus fragmentation of treated cells into structures similar to apoptotic bodies occurred in some cells only and was cell type dependent. This would indicate the independence of membrane blebbing and the formation of cell bodies. The similar results reported the authors who found that blebbing of the plasma membrane occurs independently and is not required for engulfment of apoptotic cells by macrophages (9).

\section{Conclusions}

We found that in our experimental systems treatments with cytostatic chemicals triggered membrane blebbing whose dynamics and appearance differed. Variations recorded by time-lapse videomicroscopy and fluorescence microscopy occurred both between cell populations and within them. These variations may be due to several factors such as the cell cycle distribution in treated cells, drug-dependent activation of specific signaling pathways and the expression of cytoskeleton-regulating proteins.

\section{Acknowledgement}

This work was supported by Ministry of Education Czech Republic Research Project MSM 0021620820.

\section{References}

1. Bailly C. Topoisomerase I poisons and suppressors as anticancer drugs. Curr Med Chem 2000;7:39-58.

2. Coleman ML, Sahai EA, Yeo M, Bosch M, Dewar A, Olson MF. Membrane blebbing during apoptosis results from caspase-mediated activation of ROCK I. Nat Cell Biol 2001;3:339-45.

3. Kravtsov VD, Daniel TO, Koury MJ. Comparative analysis of different methodological approaches to the in vitro study of drug-induced apoptosis. Am J Pathol 1999;155:1327-39.

4. Kroemer G, Petit P, Zamzami N, Vayssiere JL, Mignotte B. The biochemistry of programmed cell death. The Faseb Journal: Official Publication of the Federation of American Societies For Experimental Biology 1995;9:1277-87.

5. Mills JC, Stone NL, Erhardt J, Pittman RN. Apoptotic membrane blebbing is regulated by myosin light chain phosphorylation. J Cell Biol 1998;140:627-36.

6. Rudolf E, Peychl J, Novak J, Cervinka M. Apoptosis - when the cells begin to dance. Front Biosci 2000;5:F1-2.

7. Sargent JM, Elgie AW, Williamson CJ, Hill BT. Ex vivo effects of the dual topoisomerase inhibitor tafluposide (F 11782) on cells isolated from fresh tumor samples taken from patients with cancer. Anticancer Drugs 2003;14:467-73.

8. Sebbagh M, Renvoize C, Hamelin J, Riche N, Bertoglio J, Breard J. Caspase3-mediated cleavage of ROCK I induces MLC phosphorylation and apoptotic membrane blebbing. Nat Cell Biol 2001;3:346-52.

9. Shiratsuchi A, Mori T, Nakanishi Y. Independence of plasma membrane blebbing from other biochemical and biological characteristics of apoptotic cells. J Biochem (Tokyo) 2002;132:381-86.

10. Song Y, Hoang BQ, Chang DD. ROCK-II-induced membrane blebbing and chromatin condensation require actin cytoskeleton. Exp Cell Res 2002;278:45-52.

11. Tomiyoshi G, Horita Y, Nishita M, Ohashi K, Mizuno K. Caspase-mediated cleavage and activation of LIM-kinase 1 and its role in apoptotic membrane blebbing. Genes Cells 2004;9:591-600. 
12. van Gorp RM, Heeneman S, Broers JL, Bronnenberg NM, van Dam-Mieras MC Heemskerk JW. Glutathione oxidation in calcium- and p38 MAPK-dependent membrane blebbing of endothelial cells. Biochim Biophys Acta 2002;1591: 129-38.

13. Wang L, Eastmond DA. Catalytic inhibitors of topoisomerase II are DNA-damaging agents: induction of chromosomal damage by merbarone and ICRF-187. Environ Mol Mutagen 2002;39:348-56.

14. Yuste VJ, Bayascas JR, Llecha N, Sanchez-Lopez I, Boix J, Comella JX. The absence of oligonucleosomal DNA fragmentation during apoptosis of IMR-5 neuroblastoma cells: disappearance of the caspase-activated DNase. J Biol Chem 2001; 276:22323-31

Submitted January 2005.

Accepted March 2005.

PharmDr. Emil Rudolf, Ph.D.,

Charles University in Prague,

Faculty of Medicine in Hradec Králové,

Department of Medical Biology and Genetics,

Šimkova 870, 50038 Hradec Králové,

Czech Republic.

e-mail: rudolf@lfhk.cuni.cz 